Journal of Economic,

Administrative and Legal Sciences

Volume (6), Issue (2): 30 Jan 2022

P: 29 - 46
AJSRP

ISSN: 2522- 3372
مجلة العلوم الاقتصبادية

والإدارية والقانونية

المجلد (6)، العدد (2): 30 يناير 2022 م

ص: 29 - 46

\title{
The impact of career planning and development on improving employee performance in the General Authority for Applied Education and Training in the State of Kuwait
}

\section{Haytham Abdul Gafur Makhseed}

\author{
Higher Institute of Administrative Services || Public Authority for Applied Education and Training || Kuwait
}

\begin{abstract}
This study aims to know the impact of planning and career development on the performance of employees of the Public Authority for Applied Education and Training in the State of Kuwait, and to highlight the extent of the impact of the concept of planning and development in order to understand the career path and its importance among employees. The descriptive analytical approach was applied, the researcher designed a questionnaire to collect the required data and work and it was analyzed through the use of the SPSS statistical analysis program, and the questionnaires were distributed to a sample The randomized study, which numbered (50) male and female employees, (46) copies were recovered, i.e. (92\%) of the total sample. One of the most important findings of this study was that the level of work performance as evaluated by employees is low with a correlation between career planning and work performance, and the level of career planning is low according to the evaluation of employees of the Public Authority for Applied Education and Training, and there are no significant differences Statistical significance in the axes of career planning and work performance according to age, experience or training courses. The study concluded with a set of recommendations, including:

* To pay attention and work to improve the job vacancy system in force in the Public Authority for Applied Education and Training in the State of Kuwait.

* Urging employees to know the importance of applying career planning systems and raising awareness of their importance and the benefits that can be achieved for all, with the need to pay attention to motivational systems and methods.

* The need to provide an adequate database for current and future career paths.

* Encouragement to conduct more scientific research to reach the best methods to achieve an increase in the job performance of employees
\end{abstract}

Keywords: Career planning, Employee performance, Career path, Job design, Development strategy, Training.

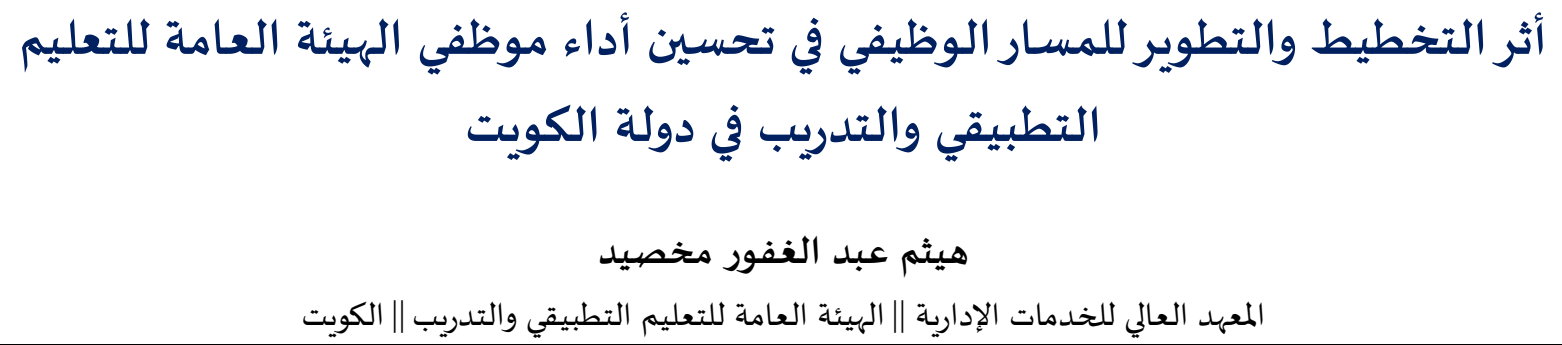

المستخلص: هدفت هذه الدراسة إلى معرفة أثر التخطيط وتطوير المسار الوظيفي في تحسين أداء العاملين بالهيئة العامة للتعليم التطبيقي والتدريب في دولة الكويت، وإبراز مدى تأثير مفهوم التخطيط والتطوير ليتم فهم المسار الوظيفي وأهميته بين الموظفين. وقد تم تطبيق المنهج الوصفي التحليلي، حيث قام الباحث بتصيميم استبانة لجمع البيانات المطلوبة والعمل وتم تحليلها من خلال استخدام 
برنامج التحليل الإحصائي SPSS، وقد تم توزيع الاستبانات على عينة الدراسة بالطريقة العشوائية والبالغ عددها (50) موظفا وموظفة إنيا

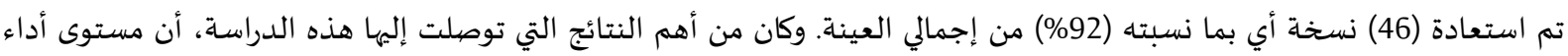

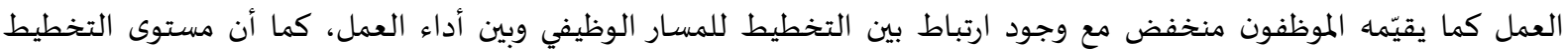

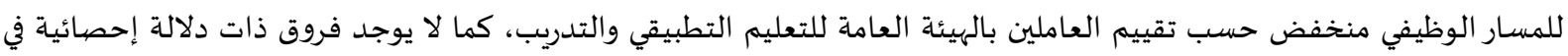

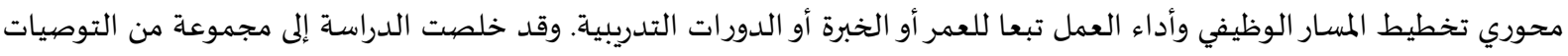
* أن يتم الاهتمام والعمل على تحسين نظام شغور المناصب الوظيفية المعمول بهاه بالهيئة العامة للتعليم التطبيقي والتدريب في دولة * حث العاملين على معرفة أهمية تطبيق أنظمة تخطيط المسار الوظيفي وزيادة التوعية بأهميتها وما يمكن أن يتحقق من المنافع للجميع مع ضرورة الاهتمام بنظم وأساليب التحفيز. * ضرورة توفير قاعدة بيانات كافية للمسارات الوظيفية الحالية والمستقبلية.

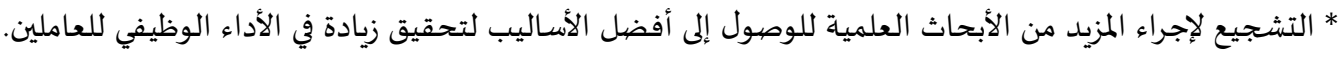
الكلمات المفتاحية: التخطيط الوظيفي، أداء الموظفين، المسار الوظيفي، تصميم الوظائف، استراتيجية التطوير، التدريب

مقدمة.

تعتبر الموارد البشرية من أهم عناصر التطور والنمو في المنظمات الحديثة، فالموارد البشرية تعتبر مصدرا

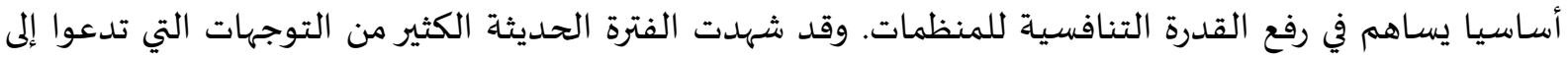

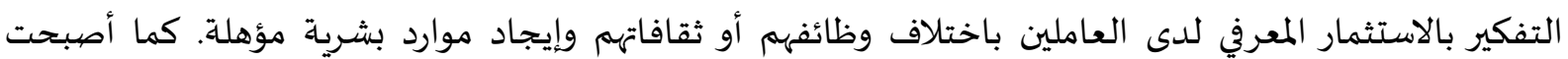

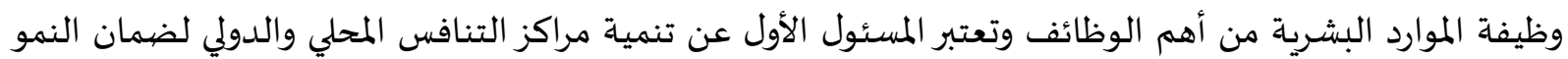
والإبداع. (السعدي، 2018: 8- 22)

كما رأى الكثير من الباحثين ضرورة توافق استراتيجيات الموارد البشرية وباقي استراتيجيات العمل في المنظمة

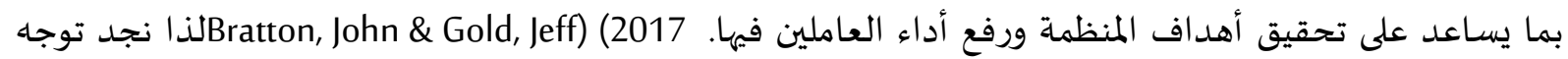
غالبية المسئولين في كثير من المنظمات، باختلاف أنواعها وأنشطتها وأهدافها، هو التركيز على أداء العاملين في إناء

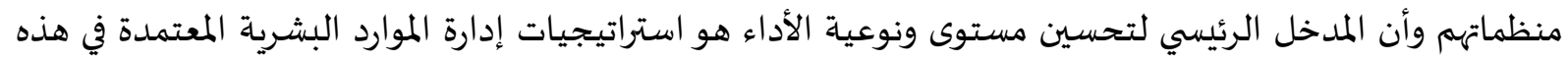
المنظمات. (Cascio, 2018)

وقد تزايد الاهتمام بالموارد البشرية كأحد وأهم عناصر البقاء للمنظمات واعتبر العنصر البشري الركن

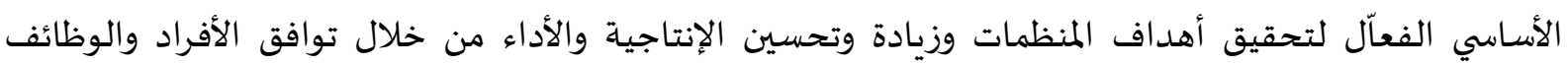

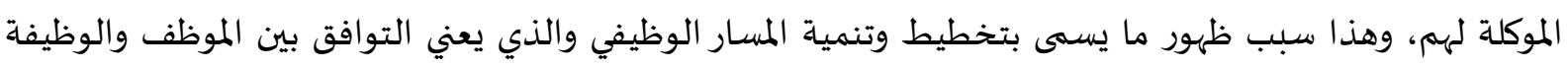

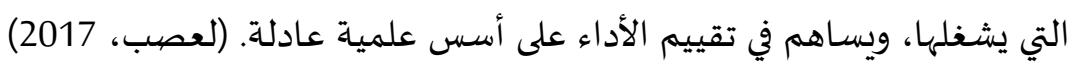

مشكلة الدراسـة

تتلخص مشكلة الدراسة في معرفة ما يلي:

إلى أي مدى يمكن أن تساهم عملية التخطيط والتطوير الوظيفي (كأدوات محفزة للعنصر البشري) في معاتي تحسين أداء موظفي الهيئة العامة للتعليم التطبيقي والتدريب في دولة التهائة الكويت.

للإجابة على المشكلة الرئيسية، تم طرح الأسئلة التالية:

1- ما درجة تقييم تخطيط المسار الوظيفي من قبل الموظفين الهيئة العامة للتعليم التطبيقي والتدريب في دولة

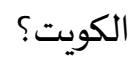

أثر التخطيط والتطوير للمسار الوظيفي على تحسين أداء الموظفين المبدار المظئ 
2- ما درجة تقييم مستوى أداء العمل من قبل العاملين بالهيئة العامة للتعليم التطبيقي والتدريب في دولة

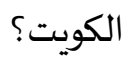

3- ما أثر التخطيط والتطوير الوظيفي في تحسين أداء العاملين بالهيئة العامة للتعليم التطبيقي والتدريب؟

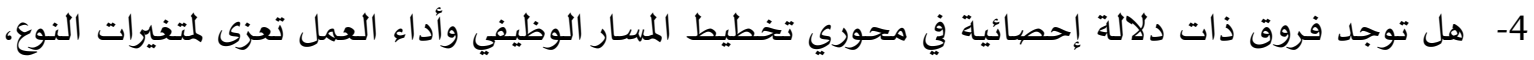

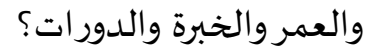

\section{فرضيات الدراسة}

1. للدورات التدريبية أثر إيجابي لفهم ومعرفة دور التخطيط والتطوير الوظيفي في تحسين أداء العمل. 2. أنشطة التخطيط الوظيفي من حيث التخطيط والتطوير هي مفاتيح لتقييم وتحسين أداء الموظفين. 3. يساهم تخطيط وتطوير المسار الوظيفي في تقييم أداء الموظفين بطريقة مناسبة.

4. وجود علاقة ذات دلالة إحصائية بين متطلبات التخطيط والتطوير الوظيفي في تقويم وتقييم تحسين أداء

العاملين بالهيئة.

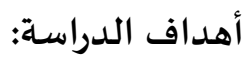

1 1. التعرف على مفهوم التخطيط الوظيفي للموظفين. 2. دراسة واقع التطور الوظيفي وعلاقته بأداء الموظفين.

3. التعرف على الدور الفعال للتخطيط الوظيفي في أداء العاملين بالهيئة العامة للتعليم التطبيقي والتدريب التهاء 4. - معرفة مفهوم التخطيط الوظيفي.

5. بيان أهمية التخطيط وتطوير المسار الوظيفي ودوره في تحسين أداء الموظفين. 6. معالجة نقص الوعي لدى العاملين بأهمية التخطيط لمسارهم الوظيفي والاهتمام به.

أهمية الدراسة

تكتسب الدراسة أهميتها من أهمية ودور التخطيط لتطوير المسار الوظيفي في المساهمة لزيادة إنتاجية

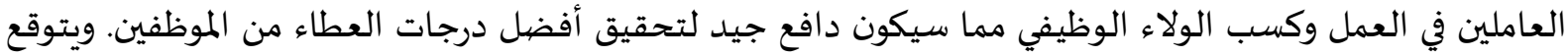
الباحث أنه من خلال هذه الدراسة سيتم إيضاح الدور الهام الذي يلعبه التخطيط للمسارات الوظيفية للعاملين.

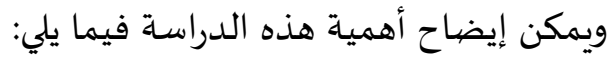
الأهمية العلمية: زيادة اهتمام القيادات الإدارية على حث العاملين بضرورة فهم ومعرفة وتطبيق التخطيط لتطوير المسارات الوظيفية، كما ستساهم الدراسة في تنشيط وزيادة المهارات والمعارف لدى العاملين من خلال الإطلاع على النظم والأساليب الحديثة والعمل على توظيف ما يصلح منها في تطبيق عملية التخطيط لتطوير المسارات الوظيفية. الأهمية النظرية: أن هذه الدراسة تعتبر من الدراسات الأولى في هذا الحقل وخصوصا في الهيئة العامة للتعليم

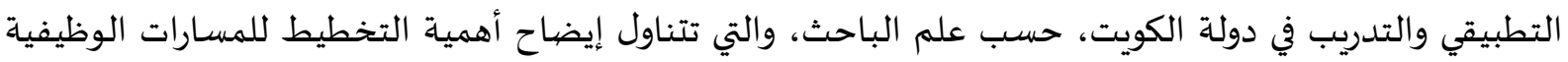
في العمل ودورها في تحقيق إنتاجية أفضل من العاملين. 
الحدود البشرية: موظفي الهيئة العامة للتعليم التطبيقي والتدريب.

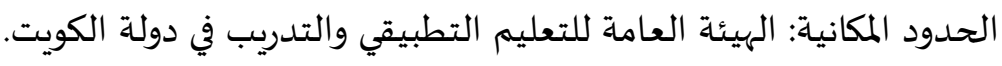

الحدود الزمنية: العامين الجامعيين؛ 2020/2019؛ 2021/2020.

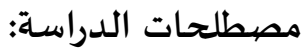

- التطوير الوظيفي: "الأنشطة التي يقوم بها الموظفين أنفسهم والمنظمة لتحقيق الأهداف المهنية ومتطلبات

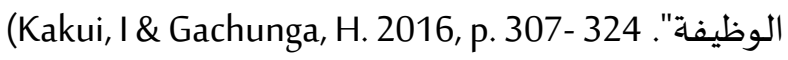

- - المسار الوظيفي: "سلسلة من الوظائف ذات الصلة مرتبة حسب الحالة والمسئولية". (Felix, K, 2012)

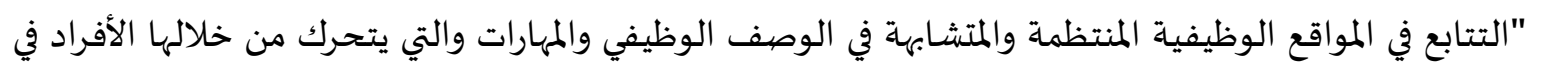
المنظمة". (عباس، 2006: 214) تخطيط المسار الوظيفي: الجهود المبذولة من إدارة الموارد البشرية بالتعاون مع الموظف لتوظيف المعارف والمهارات والقدرات وأي خصائص أخرى يتمتع بها الموظف من أجل تحقيق التقدم الوظيفي". (مصلح، 2018)

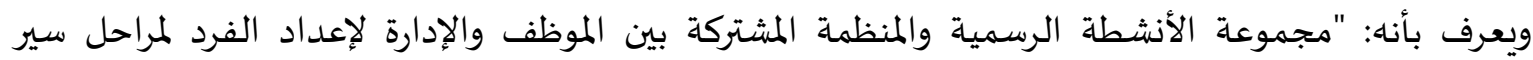
وظيفي متصاعدة وتحديد المهارات المطلوبة للتوفيق بين أهداف الفرد والمنظمة وتشمل كافة المستويات

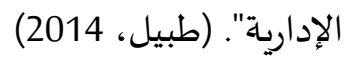

- التقدم الوظيفي: "عملية تقدم مهنة الفرد ونموه الوظيفي والترقيات الوظيفية". (Chanin, Y. 2012)

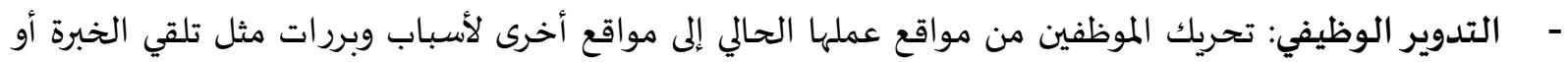

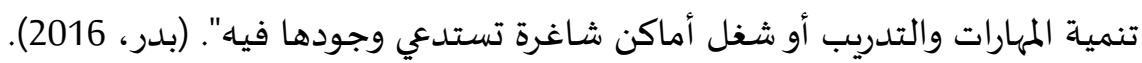
- الأداء الوظيفي:"درجة إنجاز وإتمام المهام المكونة لوظيفة الفرد وهو يعكس الكيفية التي يحقق أو يشبع بها الفرد متطلبات الوظيفة، فهو سلوك يسعى للوصول إلى هدف معين، وتختلف النظرة الإداريّة للأداء الوظيفيّ،

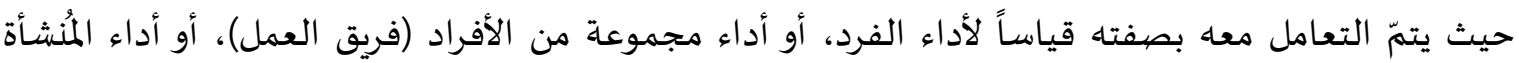

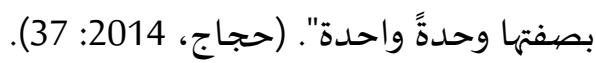

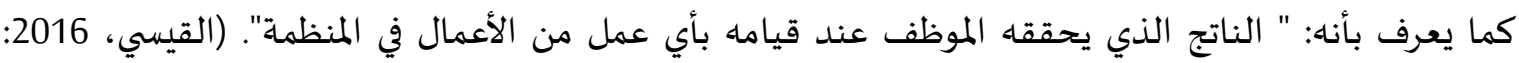

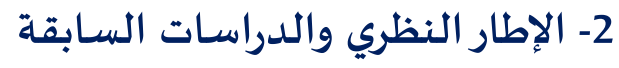

$$
\text { تخطيط وتنمية المسـار الوظيفي وأداء الموظفين }
$$

يعتبر العنصر البشري محور رئيسي للعملية الإدارية ويهدف من تخطيط وتنمية وتطوين وارئ المسيار الوظيفي

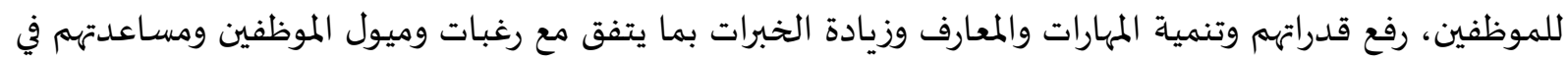
تحقيق أهداف العاملين الشخصية من خلال تحقيق الأهداف العامة للمنظمة.

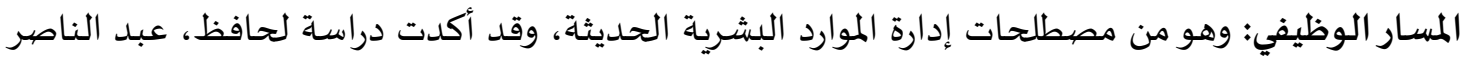

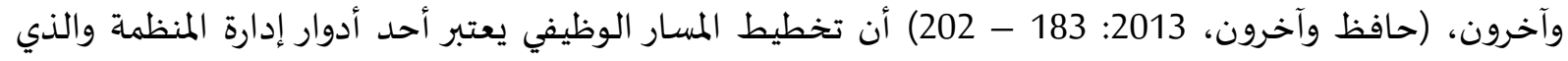

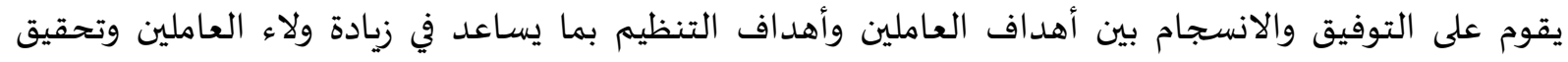
الأهداف التنظيمية في المنظمة. كما أوضحت دراسة عثمان وفتحي (عثمان ومعيوش، 2016) بأن المسار الوظيفي ما ولاء 
هو إلاسلسلة متعاقبة من التغييرات الوظيفية التي تحدث في الحياة العملية للعاملين أو قد تكون مجموعة الوظائف

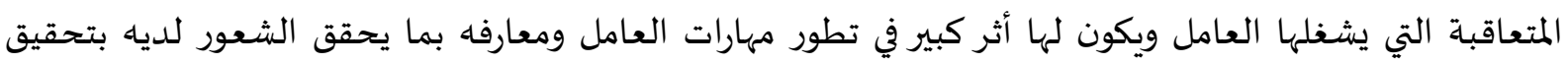
إنجازات تتفق وآماله وطموحاته.

التخطيط: وهو الركن الأساسي الأول للعملية الإدارية ويتمثل في تحديد وبلورة الأهداف بشكل دقيق ويمكن وصفه بأنه المنهج الإنساني الذي تقوم باه إدارة المنظمة لتحقيق الأهداف تحقيقها من خلال اتخاذ القرارات الإيجابية

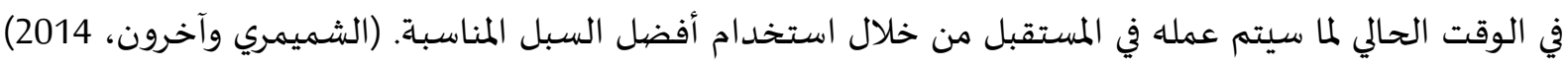

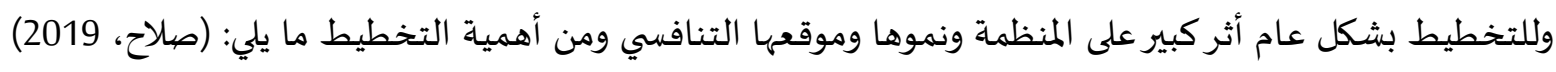

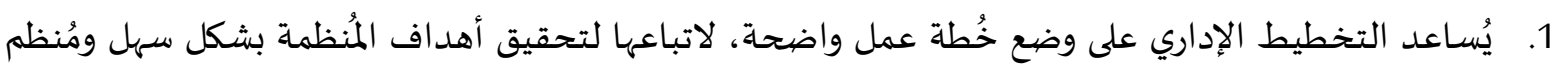

ضمن معايير واضحة.

2. توجيه طاقات المدراء والموظفين إلى إنجاز العمل ضهمن الخُطة المطروحة.

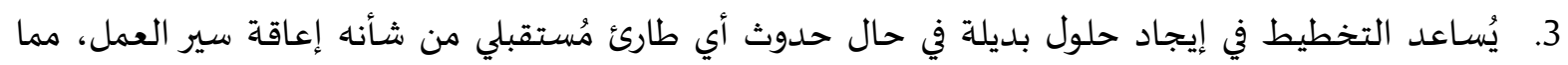

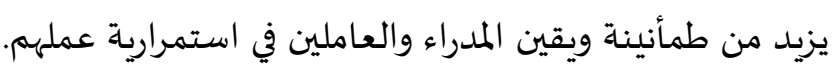

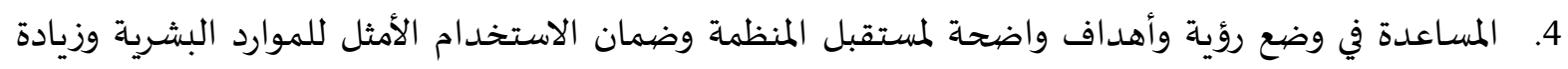

كفاءتها وقدرتها على الإنتاجياة.

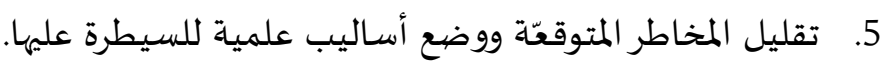

تخطيط المسار الوظيفي:

وهي عملية تنظيمية تقوم بها إدارة الموارد البشرية في المنظمة يتم من خلالها رسم الأطر العامة لمستقبل

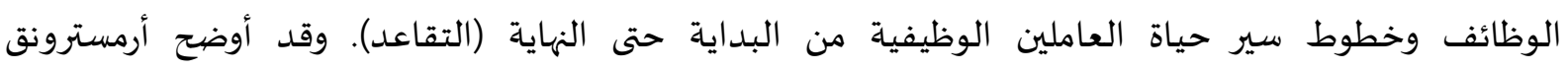
(Armstrong, M. 2016 , p. 695) Armstrong

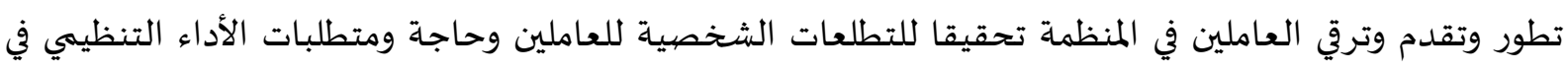

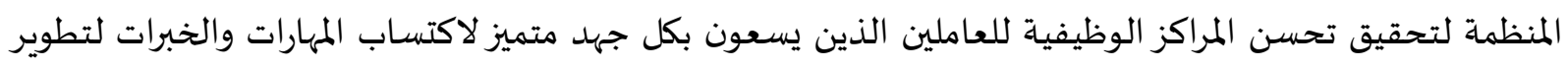
أدأهه الوظيفي التي تتطلها الوظائف الحالية والمستقبلية. (26 -10 , Biswakarma, Gangaram, 2016)

مسئولية تخطيط المسار الوظيفي: يتقاسم الموظف والمنظمة التي يعمل بها مسئولية التخطيط ورسم المسارات الوظيفية، ولابد أن يلعب المبار المبات الأفراد دورا في التخطيط لمستقبلهم الوظيفي بما يتناسب مع مؤهلاتهم ومهاراتهم واتجاهاتهم وطموحاتهم المستقبلية

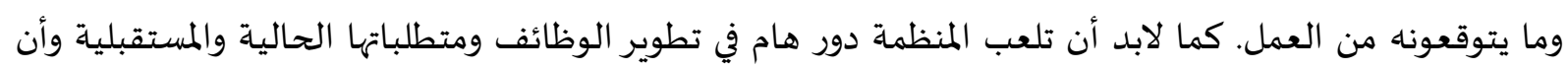

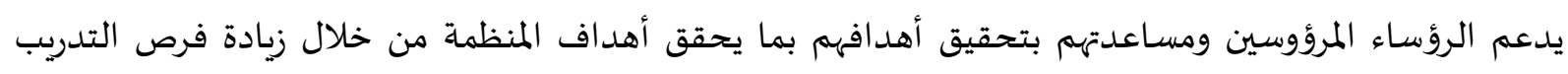

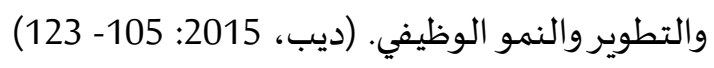

أهمية تخطيط المسار الوظيفي:

يتضح مما سبق بأن أهمية التخطيط للمسار الوظيفي سوف يعود بالنفع على أطرافه (الموظف والمنظمة) من خلال تحقيق الأهداف المستقبلية لكل منهم. وقد أوجزت الباحثة ندى مصلح هذه الأهمية فيما يلي: (مصلح، ندى إبراهيم، 2018: 24) 
تحقيق أهداف الموظفين والمنظمة من خلال إشباع طموحات الموظفين مما سيحقق الرضا الوظيفي لدهيم

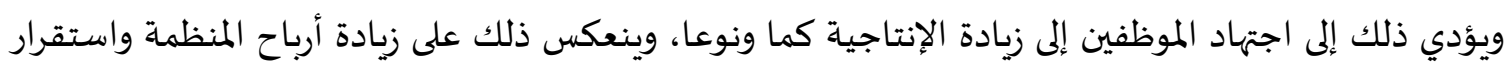
العمل فيها مما يزيد في قدرتها التنافسية. الحد من الجمود الوظيفي من خلال استخدام المنظمة للطرق الديناميكية المهنية التي تتضمن الترقيات

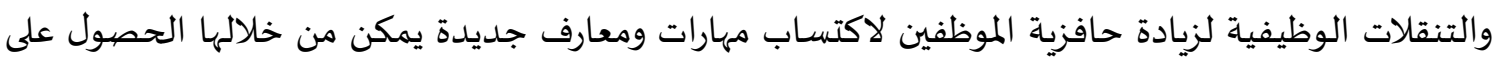
فرص الترقي. زيادة جاذبية المنظمة للطاقات والكفاءات من جهات منافسة بسبب السمعة الجيدة التي تنتشر في أوساط العاملين المؤهلين، مما يعني اجتذاب الكفاءات من خارج المنظمة وزيادة الولاء والانتماء للعاملين داخل المنظمة.

الاستقرار النفسي للعاملين في المنظمة مما سيكون له أثر إيجابي جيد في زيادة العطاء نتيجة وضيوح المسار الوظيفي للموظف.

$$
\text { مفهوم الأداء الوظيفي }
$$

يتمثل الأداء الوظيفي في قيام الفرد بمجموعة من الأنشطة والمهام المختلفة التي يتكون منها عمله، والذي

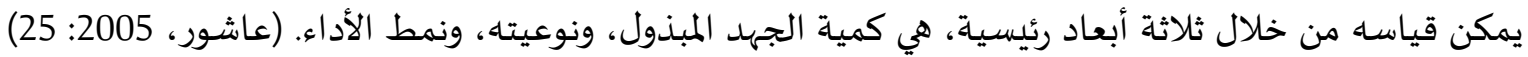
ويشير مفهوم الأداء إلى درجة تحقيق وإتمام المهام المكونة لوظيفة الفرد بما يضمن النوعية والجودة المطلوبة وبكفاءة وفعالية ووفقا للمعدل المفروض أداءه من الموظف. (سليماني وجرار، 2019).

$$
\text { • • مكونات الأداء الوظيفي }
$$$$
\text { نوعية العمل من خلال تحديد ماهيته وصفته (مكتبي أو فني). }
$$$$
\text { كمية العمل المراد إنجازها في الظروف العادية (الكم والفترة الزمنية المستغرقة). }
$$

المثابرة والتي تتحقق من خلال الدافع للعمل ودرجاته، وهو نتيجة تفاعل ثلاثة عوامل هي الظروف الجسمية

$$
\text { والصحية، والظروف المحيطة. }
$$

العوامل المؤثرة على الأداء

$$
\text { من أهم العوامل المؤثرة على الأداء ما يلي: (بن زاف، 2015: 2015: 59- 70) }
$$

$$
\text { غياب الأهد اف المحددة أو عدم وضوحها. }
$$

عدم مشاركة الفرد في الإدارة سواء كاستشارة أو ممارسة.

مشكلات الرضا الوظيفي (كلما زاد معدلات الرضا، سوف يكون ذلك دافع لزيادة الأداء).

$$
\text { تقييم الأداء (عودة، 2018: 103- 118) }
$$

تعد عملية تقييم الأداء من العمليات الهامة التي يجب أن تمارسها إدارة الموارد البشرية بالطرق العلمية

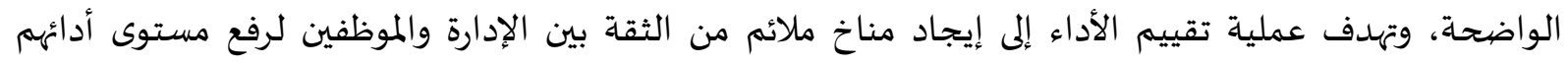

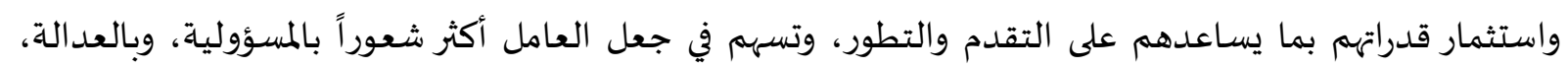


وبأن جميع جهوده المبذولة تأخذ بالحسبان من قبل المنظمة، وتدفع بالموظف للعمل باجتهاد وجدية وإخلاص ليكسب تقدير رؤسائه معنويا وماديا.

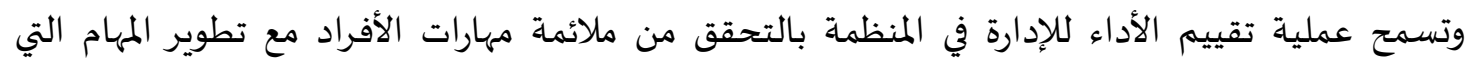

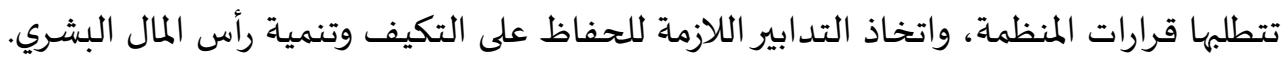

ثانياً - الدراسـات السـابقة - دراسة قوراري والعياشي، (2019) وهدفت الدراسة للتعرّف على واقع التدوير الوظيفي وأثره في تحسين الأداء حيث تم دراسة أربعة من متطلبات التدوير الوظيفي وهي التدريب - تصميم الوظائف - الاستقطاب -

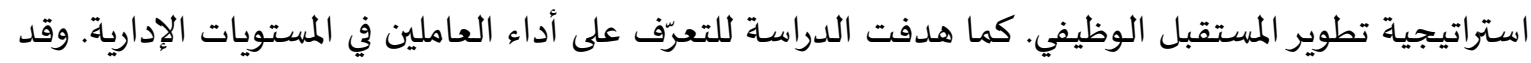

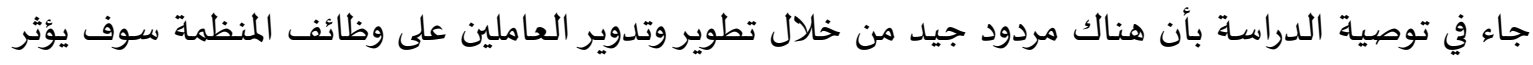

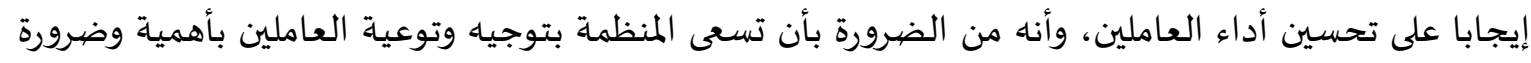
العمل على تحسين الأداء. دراسة Gajanethi Swathi Kumari (2019) وهدفت هذه الدراسة إلى معرفة أثر ممارسات الموارد البشرية في كل من القطاع العام والقطاع الخاص للاتصالات في الهند وتحليل أثرها على الرضا والتطوير الوظيفي للعاملين.

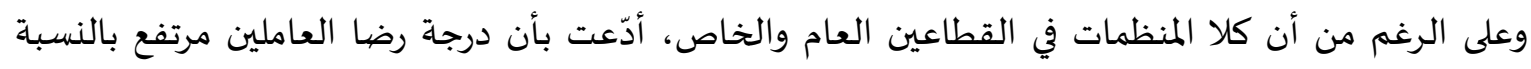

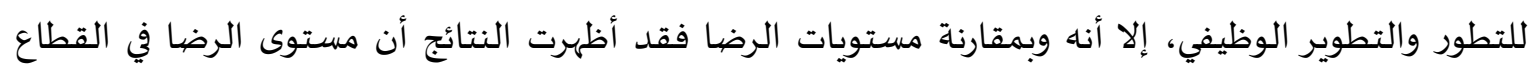

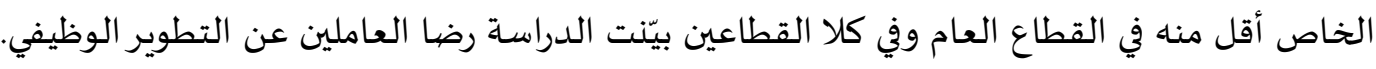
دراسة غضببان وعولمي، (2019) وقد هدفت الدراسة الكشف عن دور المسار الوظيفي في تحسين أداء العاملين

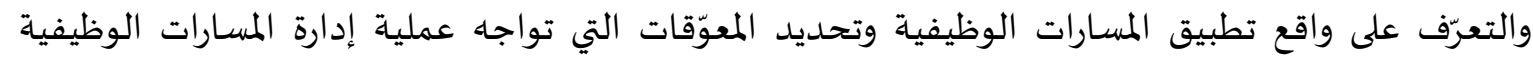

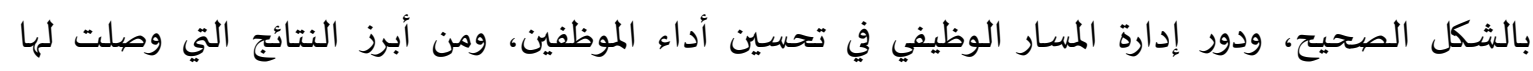

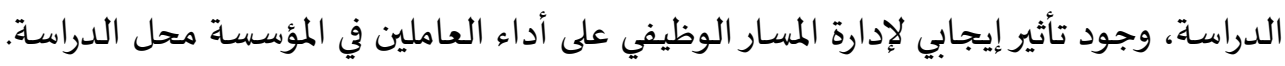
دراسة Wayan Manggis وآخرون (2018) وهدفت الدراسة إلى معرفة أثر التطوير الوظيفي وقيادة أداء

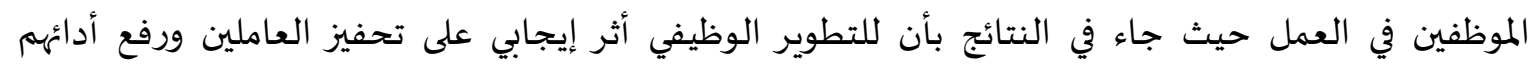

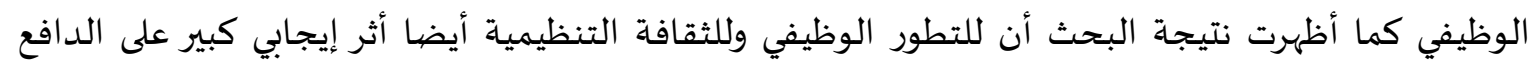
للعمل وعلى أداء الموظفين والحث على زيادة العطاء والإنتاجية. دراسة مصلح، (2018) التأقلم التنظيمي كمتغير وسيط لقياس العلاقة بين تخطيط المسار الوظيفي والاحتراق الوظيفي، وهدفت الدراسة إلى قياس العلاقة بين تخطيط المسار الوظيفي المتمثلة في وضع أهداف التقدئ التمام

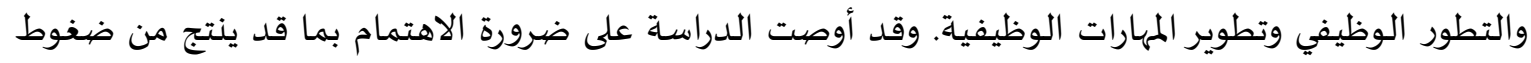

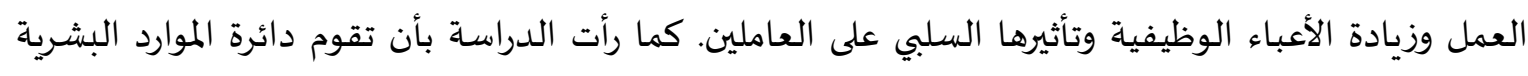

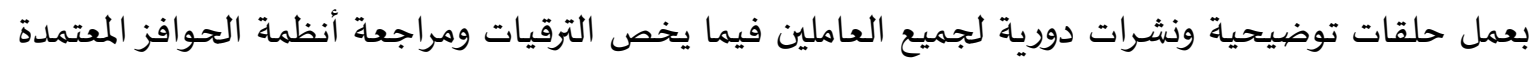

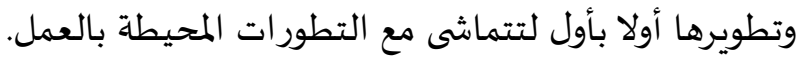
دراسة لعصب، (2017) وقد هدفت الدراسة لمعرفة أثر تخطيط وتطوير المسار الوظيفي في أداء العاملين ولإبراز

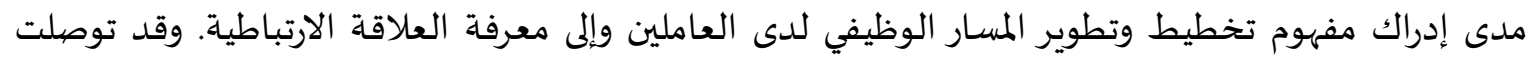
الدراسة إلى أن أغلب العاملين في حاجة ماسة دورات تدريبية تساعد العاملين في التخطيط لمساراتهم الوظيفية وإلى زيادة جهد الرؤساء في تطوير المسارات الوظيفية للعمل. 
دراسة Hedge and Rineer (2017) وهدفت هذه الورقة البحثية تشجيع وجهات نظر جديدة حول المسارات الوظيفية في أماكن العمل المختلفة مما يساعد على تحسين فهم العوامل التي تساعد وتشجع على تنمية

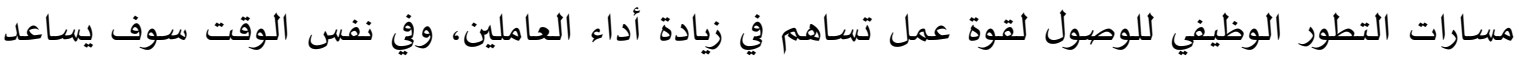

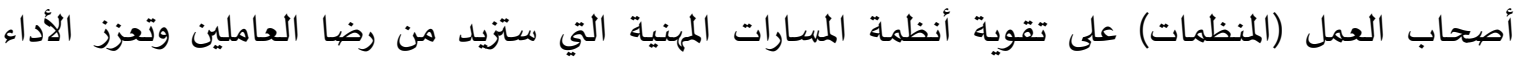
التنظيمي من خلال دعم النمو والتطوير للموظفين وانتهت الدراسة إلى أنه في حال وصول المهات المنظمات إلى إلى مسارات وظيفية جيدة للعاملين فيها فإن ذلك سيحقق الاستفادة لكل من المنظمة والعاملين حيث سيتلقى العاملين

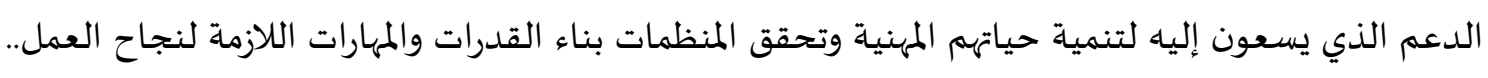
دراسة Mwashila, Harun (2017) وكان الهدف من هذه الدراسة تقييم التطوير الوظيفي على أداء أعضاء هيئة التدريس في الجامعات الحكومية الكينية وتحديد تأثير التخطيط والتقدم الوظيفي والتوجياه على أعضاء التراء التياء

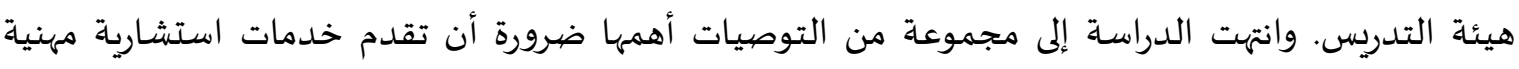

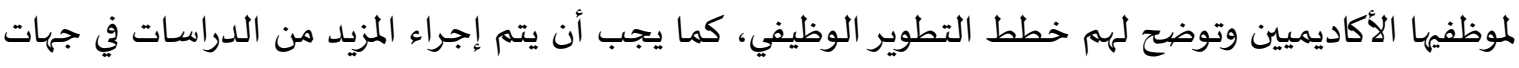

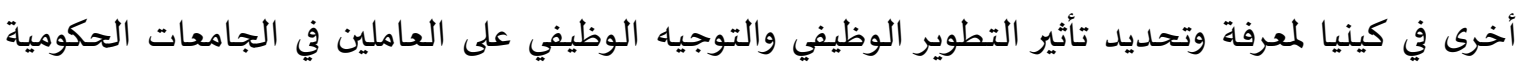
الأخرى. دراسة Ikechukwu and Paschal (2017) وهدفت الدراسة لمعرفة آثار النمو الوظيفي على أداء الموظفين غير الأكاديميين وتحديد تأثير التطوير الوظيفي والتأكد من تأثير التقدم الوظيفي على تحفيز العاملين في نيجيريا.

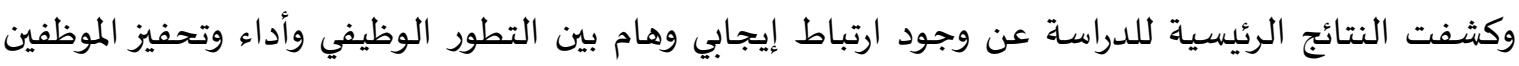

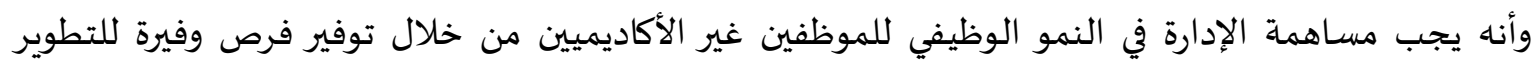

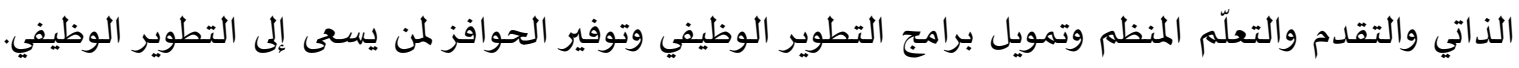

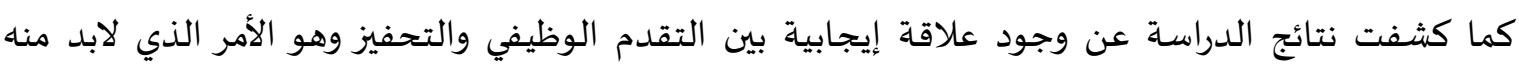

تعد الدراسات السابقة من الأجزاء الرئيسية التي لا يمكن الاستغناء عنها في هذه الدراسة نظرا للدور الذي الذيات الداتي

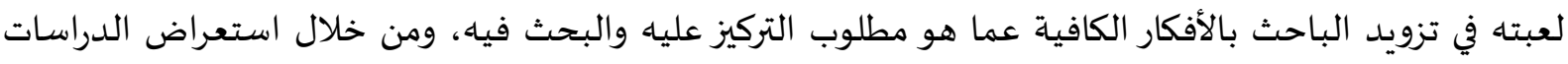
السابقة، وجد الباحث بعض وجهات التشابه في النهج العلمي مع اختلاف أهدافها ومناهج تطبيقها إلا أهنا تأصيل

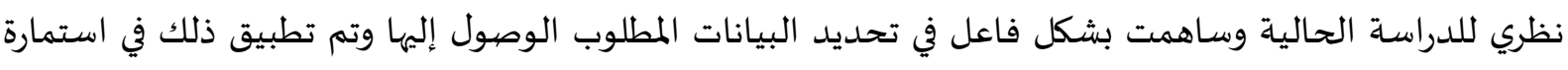

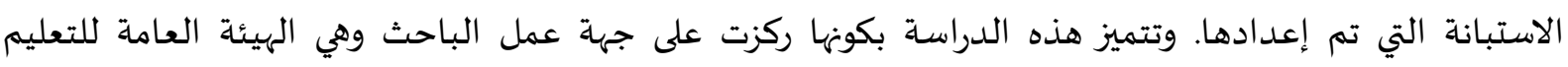

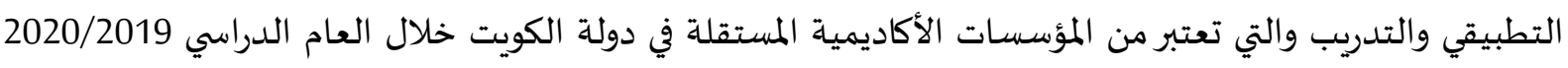
ولم يسبق تطبيق مثل هذه الدراسة من قبل حسب علم الباحث.

3- منهجية الدراسـة وإجراءاتها.

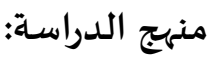

طبقت الدراسة الحالية المنهج الوصفي وذلك بالتعرف على طبيعة العلاقة بين المتغيرات المقاسة حسب

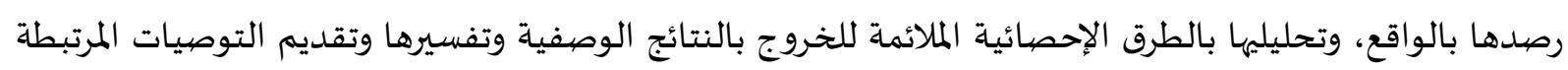


تكونت عينة الدراسـة من (46) من الموظفين في الهيئة العامة للتعليم التطبيقي والتدريب في دولة الكويت،

بلغت نسبة الاناث 60.9\%، وغالبيتهم من الجامعيين بنسبة 87\%، وتراوحت سنوات خبرتهم بين أقل من 3 سنوات إلى أكثر من 11 عام، كما تنوعوا من حيث عدد الدورات الحاصلين علهها، ويعرض الجدول (1) وصفا للعينة. جدول (1)- وصف عينة الدراسة

\begin{tabular}{|c|c|c|c|}
\hline$\%$ & العدد & الفئة & المتغير \\
\hline 39.1 & 18 & ذكر & \multirow{2}{*}{ النوع } \\
\hline 60.9 & 28 & أنثى & \\
\hline 87.0 & 40 & جامعى & \multirow{2}{*}{ المستوى التعليمى } \\
\hline 13.0 & 6 & دراسات عليا & \\
\hline 30.4 & 14 & $21-30$ & \multirow{4}{*}{ العمر } \\
\hline 34.8 & 16 & $31-40$ & \\
\hline 23.9 & 11 & $41-50$ & \\
\hline 10.9 & 5 & $50+$ & \\
\hline 8.7 & 4 & أقل من 3 سنوات & \multirow{4}{*}{ الخبرة الوظيفية } \\
\hline 28.3 & 13 & من 3- 5 & \\
\hline 15.2 & 7 & من 6 إلى 10 & \\
\hline 47.8 & 22 & أكثر من 10 سنوات & \\
\hline 13.0 & 6 & من 1- 3 & \multirow{4}{*}{ عدد الدورات } \\
\hline 19.6 & 9 & من 4- 6 & \\
\hline 19.6 & 9 & من 7- 10 & \\
\hline 47.8 & 22 & أكثر من 10 & \\
\hline 100.0 & 46 & \multicolumn{2}{|c|}{ مجموع العينة } \\
\hline
\end{tabular}

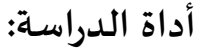

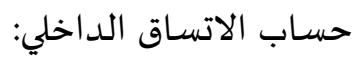

استخدم الباحث معامل ارتباط بيرسون للعلاقة بين الفقرات ومحاور لحساب الاتساق الداخلي للاستبيان، ويعرض لذلك الجدول (2) لقيم معاملات الارتباط المستخرجة.

جدول (2) معاملات الارتباط بين الفقرات ومحاور الاستبانة

\begin{tabular}{|c|c|c|c|}
\hline \multicolumn{2}{|c|}{ أداء العمل } & \multicolumn{2}{|c|}{ تخطيط المسسار الوظيفي } \\
\hline معامل الارتباط & الرقم - ال & معامل الارتباط & الرقم \\
\hline $.563^{* *}$ & 1 & $.622^{* *}$ & 1 \\
\hline $.593^{* *}$ & 2 & $.432 * *$ & 2 \\
\hline $.769 * *$ & 3 & $.543^{* *}$ & 3 \\
\hline $.593^{* *}$ & 4 & $.456^{* *}$ & 4 \\
\hline $.420^{* *}$ & 5 & $.564^{* *}$ & 5 \\
\hline $.489 * *$ & 6 & $.621 * *$ & 6 \\
\hline
\end{tabular}

أثر التخطيط والتطوير للمسار الوظيفي على تحسين أداء الموظفين المبار الوطير 


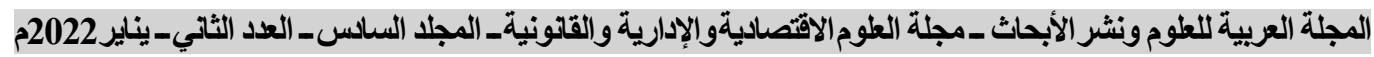

\begin{tabular}{|c|c|c|c|}
\hline \multicolumn{2}{|c|}{ أداء العمل } & \multicolumn{2}{|c|}{ تخطيط المسار الوظيفي } \\
\hline $.584^{* *}$ & 7 & $.719 * *$ & 7 \\
\hline $.430^{* *}$ & 8 & $.570^{* *}$ & 8 \\
\hline $.579 * *$ & 9 & $.732^{* *}$ & 9 \\
\hline $.384^{* *}$ & 10 & $.395^{* *}$ & 10 \\
\hline $.561^{* *}$ & 11 & $.441^{* *}$ & 11 \\
\hline $.615^{* *}$ & 12 & $.471^{* *}$ & 12 \\
\hline $.696^{* *}$ & 13 & $.357^{* *}$ & 13 \\
\hline $.473^{* *}$ & 14 & $.459 * *$ & 14 \\
\hline $.512^{* *}$ & 15 & $.461^{* *}$ & 15 \\
\hline $.775^{* *}$ & 16 & & \\
\hline
\end{tabular}

جاءت جميع معاملات الارتباط بين عبارات كل محور وبين الدرجة الكلية للمحور موجبة وذات دلالة

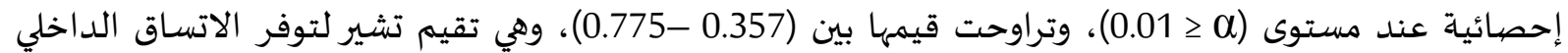
بمحوري الاستبانة.

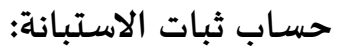

تم حساب ثبات محاور الاستبانة باستخدام كل من طريقة كرونباخ ألفا للثبات، وطريقة التجزئة النصفية، ويعرض الجدول (3) لمعاملات الثبات لمحاور الاستبانة.

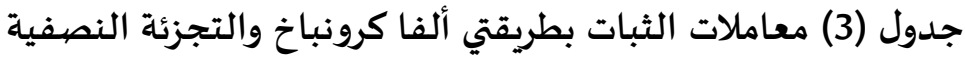

\begin{tabular}{|c|c|c|c|}
\hline التجزئة النصفية & معامل ألفا & عدد البنود & المحتور \\
\hline .712 & .701 & 15 & تخطيط المسار الوظيفي \\
\hline .724 & .713 & 16 & أداء العمل \\
\hline .732 & .73 & 31 & الاستبانة الكلى \\
\hline
\end{tabular}

تشير القيم بالجدول (3) أن معاملات ثبات الاستبانة الكلى قدر بلغت 0.73 بطريقة كرونباخ ألفا وتراوحت للمحاور بين (0.701 - 0.713)، وبلغ معامل الثبات الكلى بطريقة التجزئة النصفية 0.732 وتراوحت للمحاور بين بلين (0.724 -0.712)، وهي معاملات ثبات مرتفعة ودالة على الثبات.

الوزن النسبي المعياري:

لتحليل النتائج تم تقسيم مستويات الاستجابة على فقرات المحاور إلى المستويات التالية:

$$
\begin{aligned}
& \text { 1. من 1- } 1.80 \text { منخفض جدا } \\
& \text { 2. من 1.81- } 2.60 \text { منخفض من } \\
& \text { 3. من } 2.61 \text { - } 3.40 \text { متوسط } \\
& \text { 4. من } 3.41 \text { - } 4.20 \text { مرتفع من } \\
& \text { 5. من } 4.21 \text { - } 5 \text { مرتفع جدا }
\end{aligned}
$$

أثر التخطيط والتطوير للمسار الوظيفي على تحسين أداء الموظفين المبار الرطي 
استخدم برنامج SPSS الإصدار 24 في إدخال وتحليل البيانات واستخدمت الأساليب التالية:

$$
\begin{aligned}
& \text { 1- المتوسط الحسابي والانحراف المعياري. } \\
& \text { 2- معامل ارتباط بيرسون } \\
& \text { 3- اختبار ت للفروق بين المجموعات المستقلة } \\
& \text { 4- تحليل التباين الأحادي }
\end{aligned}
$$

4- - عرض نتائج الدراسة ومناقشتها.

نتيجة السؤال الأول: ما درجة تقييم تخطيط المسار الوظيفي من قبل الموظفين الهيئة العامة للتعليم

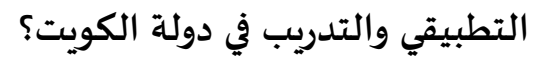

\begin{tabular}{|c|c|c|c|c|c|}
\hline 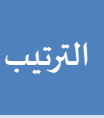 & 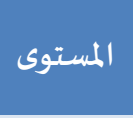 & 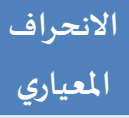 & المتوسط المسابي & 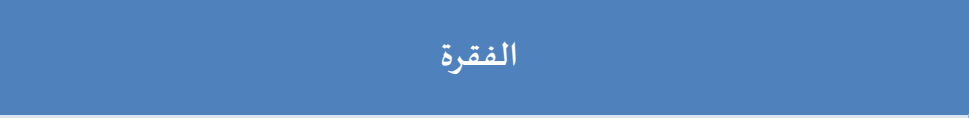 & $\hat{\imath}$ \\
\hline 1 & 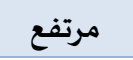 & 1.238 & 4.02 & تقييمي لمساري الوظيفي يساعد في زبادة قدراتي & 2 \\
\hline 2 & 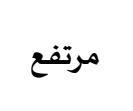 & 1.183 & 4.02 & أعتقد بأنه من الأفضل وجود مرشد في الهيئة لتتبع الموظفين ومساراتهم & 12 \\
\hline 3 & 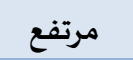 & 1.237 & 3.93 & لدي الرغبة والاستعداد لتطوير مساري الوظيفي & 6 \\
\hline 4 & 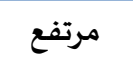 & 1.320 & 3.89 & أقوم بصفة دورية بتقييم ذاتي للمهارات التي أمتلكها & 3 \\
\hline 5 & متوسط & 1.520 & 3.04 & لدي أهداف واضحة عن مساري الوظيفي في المنظمة & 4 \\
\hline 6 & 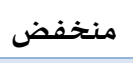 & 1.029 & 2.09 & تتناسب وتلبي المسارات الوظيفية في الهيئة، طموحات العاملين & 13 \\
\hline 7 & 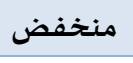 & .994 & 1.89 & تتبني الهيئة اعتماد مسارات وظيفية مرنه لمواجهة التغييرات غير المتوقعة & 11 \\
\hline 8 & \multirow[b]{2}{*}{ منخفض } & .814 & 1.78 & اجتهد للوصول لمنصبب معيّن خلال فترة معينة لمعرفتي بكامل البيانات المطلوبة & 5 \\
\hline 9 & & .696 & 1.78 & تعتمد الهيئة استراتيجية واضحة للتدريب تتوافق مع المسارات الوظيفية & 15 \\
\hline 10 & \multirow{2}{*}{ منخفض } & .612 & 1.74 & تساعد الهيئة في التخطيط لمساري الوظيفي & 1 \\
\hline 11 & & .544 & 1.72 & تدعم الهيئة استراتيجية المسارات الوظيفية من خلال تطوير وتدريب العاملين & 10 \\
\hline 12 & منخفض & .572 & 1.63 & أشعر بوجود توافق بين التخطيط الشخصي للمسار الوظيفي وتخطيط الهيئة & 7 \\
\hline 13 & \multirow{2}{*}{ منخفض } & .501 & 1.57 & 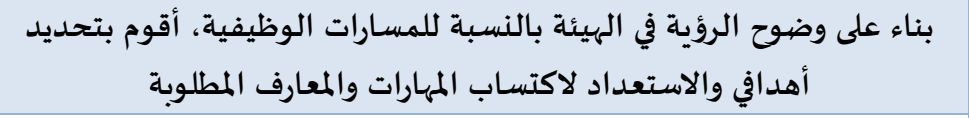 & 8 \\
\hline 14 & & .501 & 1.57 & يعلم الموظف مسبقا عن مساره الوظيفي & 14 \\
\hline \multirow[t]{2}{*}{15} & منخفض & .501 & 1.43 & توجد رؤية واضحة بالهيئة عن المناصب الوظيفية تساعد الموظفين في & 9 \\
\hline & منخفض & .236 & 2.41 & \multicolumn{2}{|l|}{ الممتوسط الكلى لمححور تخطيط المسار الوظيفي } \\
\hline
\end{tabular}

ولالجابة تم حساب المتوسط الحسابي والانحراف المعياري، والمستوى لكل من الدرجة الكلية وفقرات محور

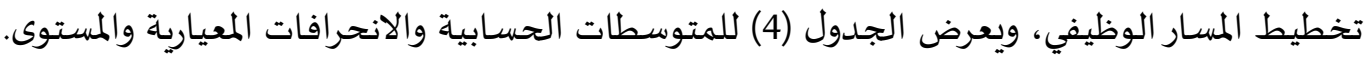

جدول (4) المتوسطات والانحرافات المعيارية والمستوى والترتيب لفقرات محور تخطيط المسار الوظيفي

أثر التخطيطوالتظوير للمسار الوظيفي على تحسين أداء 
تشير نتائج الجدول(4) إلى أن المتوسط الكلى لمحور تخطيط المسار الوظيفي هو (2.41) بما يشير إلى أن

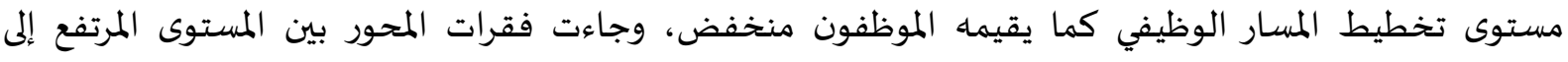
المستوى المنخفض جدا، وتراوحت قيم متوسطات الفقرات بين (4.02 - 1.43)، وجاءت 4 فقرات في المستوى لمهري المرتفع، وفقرة واحدة في المستوى المتوسط، وفقرتين في المستوى المنخفض، و8 فقرات في المستوى المنخفض جداء المقاء وجاء في الترتيب الأول الفقرة رقم 2 " تقييمي لمساري الوظيفي يساعد في زيادة قدراتي."، تلاه الفقرة رقم 12 " أعتقد

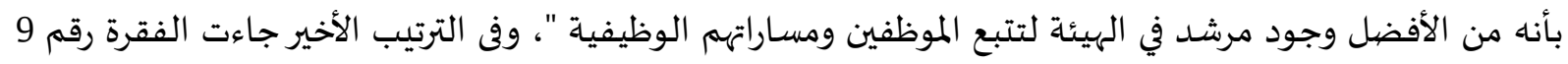
" توجد رؤية واضحة بالهيئة عن المناصب الوظيفية فودئة تساعد الموظفين في التخطيط لمساراتهم الوظيفية بشكل جيد ".

نتيجة السؤال الثاني: ما درجة تقييم مستوى أداء العمل من قبل العاملين بالهيئة العامة للتعليم التطبيقي

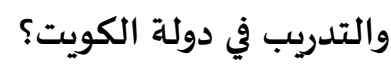
وللإجابة تم حساب المتوسط الحسابي والانحراف المعياري، والمستوى لكل من الدرجة الكلية وفقرات محور

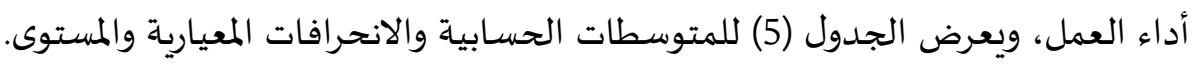

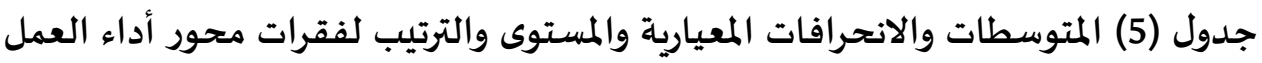

\begin{tabular}{|c|c|c|c|c|c|}
\hline الترتيب & المستوى & المياري & المتوسط & الفقرة & $\hat{r}$ \\
\hline 1 & مرتفع & .903 & 4.37 & نتائج وصححة تقييم الأداء تحفّزوتدفع الموظفين للعمل بكفاءة & 14 \\
\hline 2 & جرتفع & .737 & 4.35 & الحوافزوالتقدير تساعد في تشجيع الموظفين لبذل المزيد من الجهد في & 4 \\
\hline 3 & مرتفع & 1.278 & 3.50 & يوجد نظام عقوبات في الهيئة يؤثر سلبا على تطويروتحسين أداء الموظفين & 12 \\
\hline 4 & 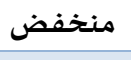 & 1.327 & 2.20 & تسعى إدارة الهيئة لتحسين وتطوير أدائها بشكل دائم ومستمر & 6 \\
\hline 5 & منخفض & 1.392 & 2.20 & 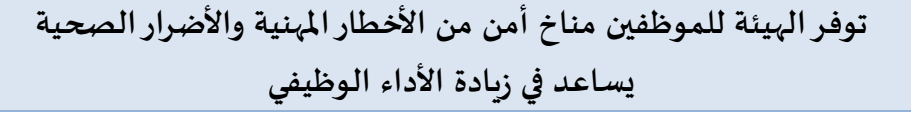 & 13 \\
\hline 6 & منخفض & 1.022 & 2.02 & يتعامل الرؤساء في العمل بشكل ودي يساعد الموظفين على تأدية أعمالهم & 15 \\
\hline 7 & 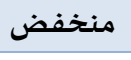 & 1.134 & 1.96 & تقوم الهيئة بمنح مكافآت للموظفين المتميزين لزيادة أدائهم في العمل & 2 \\
\hline 8 & 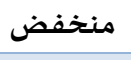 & .742 & 1.93 & تركّز الإدارة على أداء الموظفين وليس على الأخطاء التي يرتكبونها & 11 \\
\hline 9 & منخفض & .942 & 1.85 & يتوفر لدى الهيئة نظام تقييم الأداء الوظيفي بشكل مناسب وفعاّل وبشكل الموظفين لتطوير وتحسين أدائهم & 5 \\
\hline 10 & منخفض & .688 & 1.72 & يقوم الموظفون في الهيئة بتأدية أعمالهم بكفاءة وفعالية حسبما هو & 3 \\
\hline 11 & \multirow{2}{*}{ منخفض } & .604 & 1.65 & يتميّز الموظفين بسرعة اكتشاف أخطاء العمل وتصحيحها في الوقت & 7 \\
\hline 12 & & .674 & 1.65 & لدى الهيئة معاييرواضحة ومطبّقة لتحديد الأداء الوظيفي للموظفين & 16 \\
\hline 13 & \multirow{2}{*}{ منتخفض } & .501 & 1.57 & 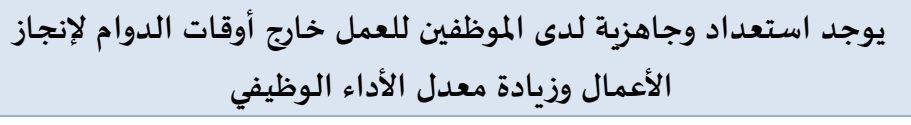 & 10 \\
\hline 14 & & .505 & 1.52 & تهتم إدارة الهيئة بالموظفين خوفا من انخفاض مستوى أداء الموظفين & 9 \\
\hline 15 & 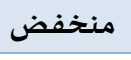 & .506 & 1.50 & تهتم الإدارة بقيام الموظفين بإنجاز الأعمال في الوقت المناسب ومتابعتهم & 8 \\
\hline
\end{tabular}




\begin{tabular}{|c|c|c|c|c|c|}
\hline الترتيب & المستوى & الانحراف & المتوسط & 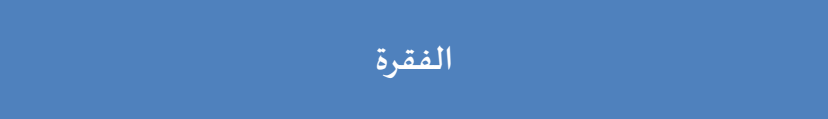 & $\hat{\imath}$ \\
\hline \multirow[t]{2}{*}{16} & جدا & .566 & 1.35 & تقوم الهيئة بعمل تقييم لأداء الموظفين بشكل دائم وبشفافية كاملة & 1 \\
\hline & 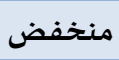 & .241 & 2.21 & المتوسط الكلى لمحور أداء العمل & \\
\hline
\end{tabular}

تشير نتائج الجدول(5) إلى أن المتوسط الكلى لمحور أداء العكل هو (2.21) بما يشير إلى أن مستوى ألماء أداء

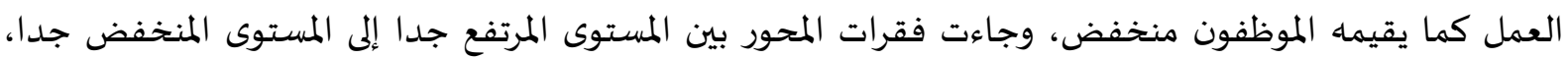

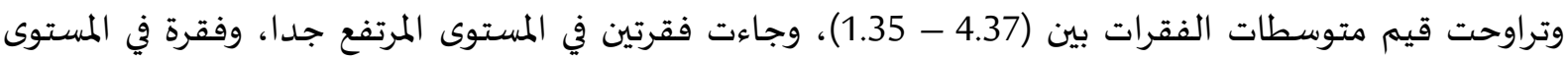
المرتفع، و6 فقرات في المستوى المنخفض، و7 فقرات في المستوى المنخفض جدا، وجاء وجاء في الترتيب الأول الفقرة رقم

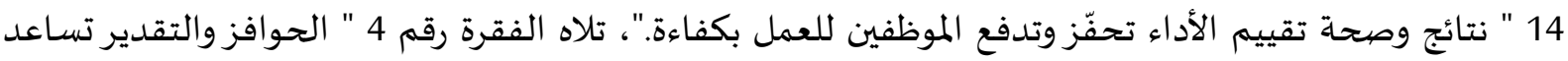
في تشجيع الموظفين لبذل المزيد من الجهد والاجتهاد في العمل "، وفى الترتيب الأخير جاءت الفقرة رقم 1 " تقوم الهيئة بعمل تقييم لأداء الموظفين بشكل دائم وبشفافية كاملة ".

نتيجة السؤال الثالث: ما أثر التخطيط والتطوير الوظيفي في تحسين أداء العاملين بالهيئة العامة للتعليم

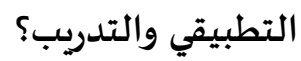

وللإجابة تم استخدم معامل ارتباط بيرسون لحساب العلاقة الارتباطية بين درجات تقييم الموظفين لكل من

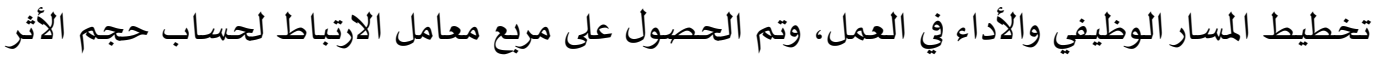
جدول (6) معامل الارتباط بين درجات تخطيط المسار الوظيفي والأداء بالعمل (ن=

\section{مجبم الأثر

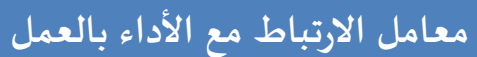

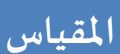

.076

$.276^{*}$

تخطيط المسار الوظيفي

دالة عند مستوى 0.05

تظهر القيم بجدول 6 وجود معامل ارتباط موجب دال إحصائيا عند مستوى (0.05) بين درجات تخطيط المسار الوظيفي، وبين أداء العمل وقد كانت قيمة معامل الارتباط ضيعيفة، وبلع حجم الأثر (7.6\%) بما يشير إلى أن تخطيط المسار الوظيفي يعود اليه (7.6\%) فقط من أداء العمل كما يقيمه الموظفين، وهو ما يشير إلى وجود ارتباط ولكن ضعيف بين تخطيط المسار الوظيفي وبين الأداء بالعمل.

نتيجة السؤال الرابع: هل توجد فروق ذات دلالة إحصائية في محوري تخطيط المسار الوظيفي وأداء العمل

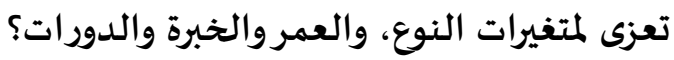

أولا- الفروق في محاور الاستبانة تبعا للنوع: استخدم اختبارت للفروق بين المجموعات المستقلة لحساب الفروق في محاور الاستبانة تبعا للنوع:

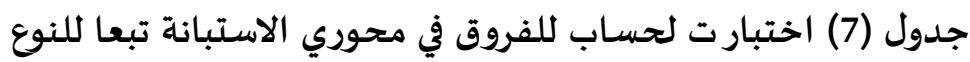

\begin{tabular}{|c|c|c|c|c|c|c|}
\hline الدلالة الإحصيائية & $ت$ & الانحراف المعياري & المتوسط الحسابي & العدد & النوع & المجالات \\
\hline \multirow{2}{*}{.558} & \multirow{2}{*}{-.590} & .244 & 2.38 & 18 & ذكر & \multirow{2}{*}{ تخطيط المسـار } \\
\hline & & .233 & 2.42 & 28 & أنثى & \\
\hline \multirow{2}{*}{.240} & \multirow{2}{*}{.653} & .204 & 2.26 & 18 & ذكر & \multirow{2}{*}{ أداء العمل } \\
\hline & & .260 & 2.17 & 28 & أنثى & \\
\hline
\end{tabular}

أثر التخطيط والتظوير للمسار الوظيفي على تحسين أداء الموظفين 
تبين نتائج الجدول (7) عدم وجود فروق ذات دلالة إحصائية تبعا للنوع في محوري الاستبانة تخطيط

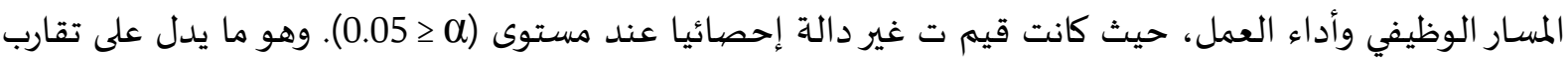
تقييم الموظفين من الجنسين لمحور الاستبانة

ثانيا- حساب الفروق تبعا للعمر: استخدم اختبار تحليل التباين One Way Anova للتعرف على تبعا لفئات العمر: جدول (8) اختبار تحليل التباين للفروق في محوري الاستبانة تبعا للعمر

\begin{tabular}{|c|c|c|c|c|c|c|}
\hline الدلالة & فيمة & متوسط المربعات & الحربة & المربعات & مصيدر التباين & المجال \\
\hline \multirow[t]{3}{*}{.423} & .954 & .053 & 3 & .159 & بين المجموعات & \multirow{3}{*}{ تخطيط المسار } \\
\hline & & .056 & 42 & 2.340 & داخل المجموعات & \\
\hline & & & 45 & 2.500 & المجموع & \\
\hline \multirow[t]{3}{*}{.279} & 1.326 & .075 & 3 & .226 & بين المجموعات & \multirow{3}{*}{ أداء العمل } \\
\hline & & .057 & 42 & 2.384 & داخل المجموعات & \\
\hline & & & 45 & 2.610 & المجموع & \\
\hline
\end{tabular}

تبين نتائج الجدول (8) عدم وجود فروق ذات دلالة إحصائية تبعا للعمر في محوري تخطيط المسار

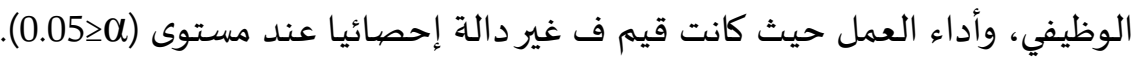

ثالثا- حساب الفروق تبعا للخبرة: - ت استخدم اختبار تحليل التباين One Way Anova للتعرف على تبعا لفئات العمر: جدول (9) اختبار تحليل التباين للفروق في محوري الاستبانة تبعا للخبرة

\begin{tabular}{|c|c|c|c|c|c|c|}
\hline الدلالة & قيمة فيمة & متوسط المربعات & الحربة درجة & المربعات & مصددر التباين & المجال ال \\
\hline \multirow[t]{3}{*}{.844} & .273 & .016 & 3 & .048 & بين المجموعات & \multirow{3}{*}{ تخطيط المسـار } \\
\hline & & .058 & 42 & 2.452 & داخل المجموعات & \\
\hline & & & 45 & 2.500 & المجموع & \\
\hline \multirow[t]{3}{*}{.829} & .294 & .018 & 3 & .054 & بين المجموعات & \multirow{3}{*}{ أداء العمل } \\
\hline & & .061 & 42 & 2.556 & داخل المجموعات & \\
\hline & & & 45 & 2.610 & المجموع & \\
\hline
\end{tabular}

تبين نتائج الجدول (9) عدم وجود فروق ذات دلالة إحصائية تبعا للخبرة في محوري تخطيط المسار الوظيفي، وأداء العمل حيث كانت قيم ف غير دالة إحصائيا عند مستوى (0.05_a).

رابعا: حساب الفروق تبعا للدورات: استخدم اختبار تحليل التباين One Way Anova للتعرف على تبعا لفئات العمر: 
جدول (10) اختبار تحليل التباين للفروق في محوري الاستبانة تبعا للدورات

\begin{tabular}{|c|c|c|c|c|c|c|}
\hline الدلالة & ف & متوسط المربعات & الحرية & المربعات & \multicolumn{2}{|c|}{ مصددر التباين } \\
\hline \multirow[t]{3}{*}{.345} & 1.137 & .063 & 3 & .188 & بين المجموعات & \multirow{3}{*}{ تخطيط المسـار } \\
\hline & & .055 & 42 & 2.312 & داخل المجموعات & \\
\hline & & & 45 & 2.500 & المجموع & \\
\hline \multirow[t]{3}{*}{.872} & .235 & .014 & 3 & .043 & بين المجموعات & \multirow{3}{*}{ أداء العمل } \\
\hline & & .061 & 42 & 2.567 & داخل المجموعات & \\
\hline & & & 45 & 2.610 & المجموع & \\
\hline
\end{tabular}

تبين نتائج الجدول (10) عدم وجود فروق ذات دلالة إحصائية تبعا للدورات في محوري تخطيط المسار

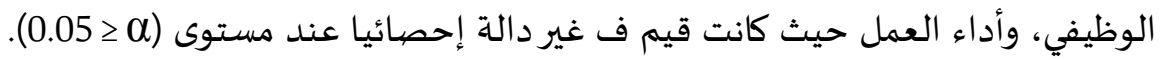

الخاتمة.

من خلال هذه الدراسة تم توضيح واقع التخطيط التطوير الوظيفي وعلاقته بأداء العاملين والدور الفعّال الذي يؤثر التخطيط الوظيفي في رفع كفاءة العمل. وقد أثبتت الدراسة أن أنشطة التخطيط الوظيفي هي مفتاح لتحسين الأداء الوظيفي للعاملين.

\section{خلاصة بأهم النتائج} - مستوى تخطيط المسار الوظيفي كما يقيمه الموظفون منخفض.

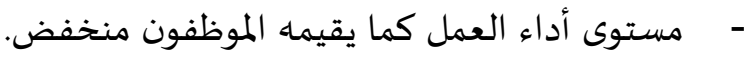

- وجود ارتباط ولكن ضعيف بين تخطيط المسار الوظيفي وبين الأداء بالعمل. وبلع حجم الأثر (7.6\%) - عدم وجود فروق ذات دلالة إحصائية تبعا للنوع في محوري الاستبانة تخطيط المسار الوظيفي وأداء العمل. - عدم وجود فروق ذات دلالة إحصائية تبعا للعمر في محوري تخطيط المسار الوظيفي، وأداء العمل. - عدم وجود فروق ذات دلالة إحصائية تبعا للخبرة في محوري تخطيط المسار الوظيفي، وأداء العمل. - عدم وجود فروق ذات دلالة إحصائية تبعا للدورات في محوري تخطيط المسار الوظيفي، وأداء العمل. التوصيات والمقترحات.

على ضوء النتائج التي خرجت بها الدراسة يوصي الباحث ويقترح ما يلي: 1. العمل على زيادة فهم ومعرفة أثر التخطيط للمسارات الوظيفية بين الموظفين. 2. حث المسئولين والموظفين على معرفة أهمية تطبيق نظام تخطيط المسار الوظيفي وزيادة التوعية بما سيعود بالنفع العام على الجميع. 3. تحسين نظام شغور المناصب والذي سيكون له الأثر الجيد على الموظفين في التخطيط لمساراتهم الوظيفية لتحقيق تطلعاتهم المستقبلية مما سوف يزيد من فاعلية الأداء الوظيفي والاجتهاد للتميّز في العمل عند الموظفين. 
4. الاهتمام بنظم وأساليب التحفيز المادي والمعنوي للموظفين والعمل على قياس كفاءة وفعالية الأداء الوظيفي بأساليب واضحة وشفافة. 5. توفير قاعدة بيانات كافية للمسارات الوظيفية الحالية والمستقبلية للموظفين ومساعدتهم للتخطيط والاجتهاد لتحقيق أهدافهم من خلال تحقيق أهداف المنظمة. 6. التخطيط العلمي الدقيق لاحتياجات المنظمة من القوى العاملة (كما وكيفا).

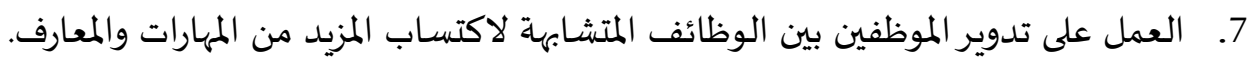

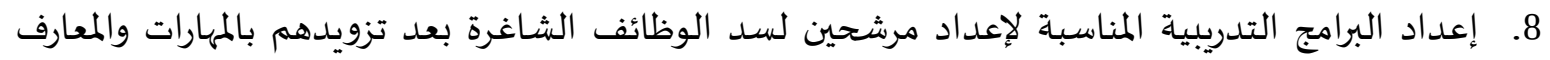
المطلوبة، وكذلك دورات تدريبية للمسئولين في المنظمة على كيفية تطبيق نظام تخطيط المسار الوظيفي وكيفية استثماره بالشكل الصحيح الفعاّل.

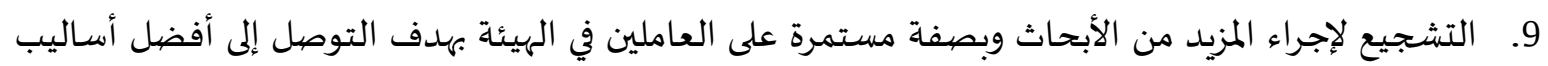
رفع الروح المعنوية بما يحقق زيادة الأداء الوظيفي.

- بدر، نظال سلام (2016) التدوير الوظيفي ودوره في الكفاءة الإنتاجية في الوزارات الفلسطينية، رسالة

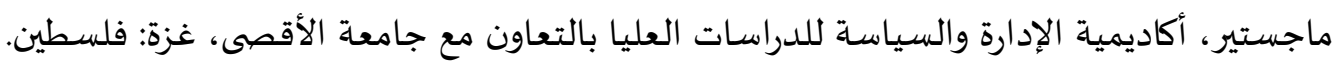

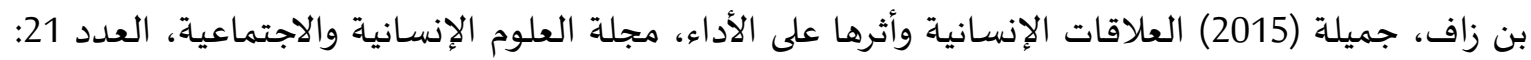
.70-59

- حافظ، عبد الناصر علك؛ حسين، وليد حسين؛ وخضير إنتهال طالب (2013) مفاهيم إدارة الجودة الشاملة

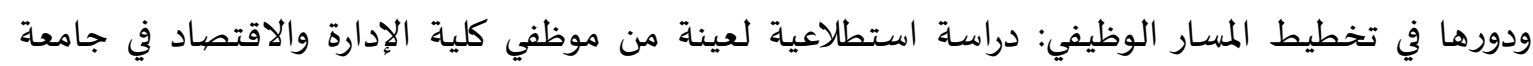

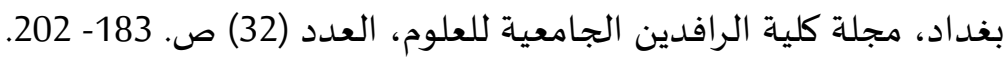

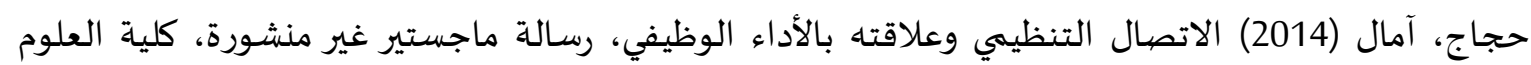

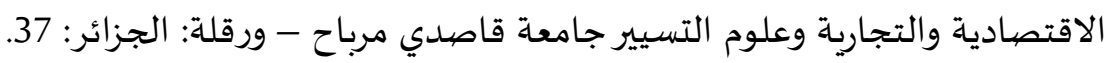

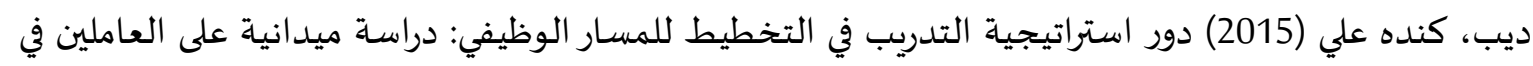

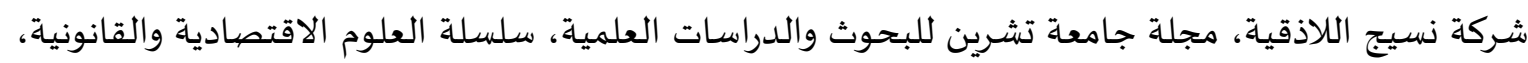
المجلد 37، العدد 3: 105- 123. - السعدي، محمد (2018) مدى توافر معايير اختيار الموارد البشرية في مدارس عدن الثدان الثانوية للموهوبين في

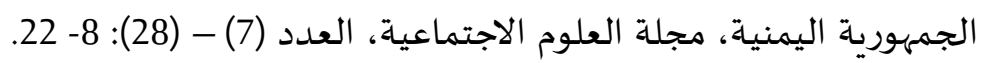

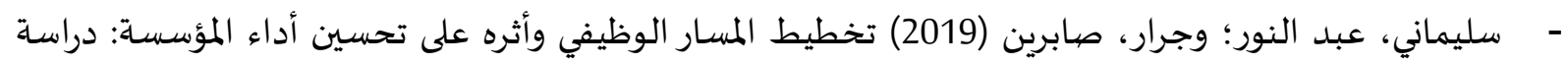

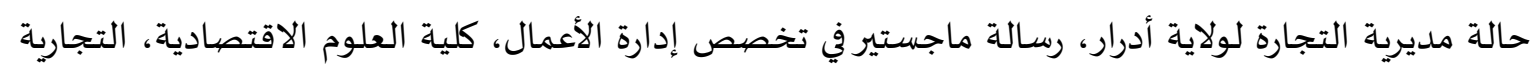
وعلوم التسيير، جامعة أحمد دراية، أدرار: الجزائر. - الشميمري، أحمد؛ وهيجان، عبد الرحمن؛ وغنام، بشرى (2014) مبادئ إدارة الأعمال: الأساسيات والاتجاهات

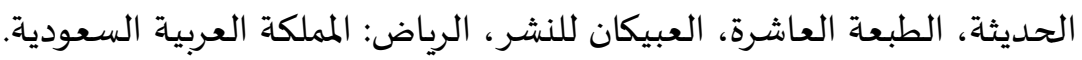


Introduction, Meaning, Importance, Features and صلاح، رزان (2019) مفهوم التخطيط الإداري، www.toppr.com ،Limitations of Planning طبيل، محمد أحمد (2014) تخطيط المسار الوظيفي وعلاقته بالفاعلية التنظيمية في وزارتي العمل والشئون

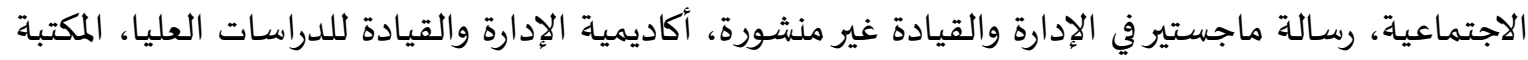
المركزية في غزة: فلسطين.

عاشور، أحمد صقر (2005) السلوك الإنساني في المنظمات، الإسكندرية، مصر، دار المعرفة الجامعية: 25 عباس، سهيلة محمد (2006) إدارة الموارد البشرية: مدخل استراتيجي، دار وائل للنشر والتوزيع، ط. 2. 2، عماّن: الأردن: 214.

عثمان، برحاب؛ وفتحي، معيوش (2016) تخطيط المسار الوظيفي: دراسة حالة مؤسسة سيرتاف مغنية، رسالة ماجستير غير منشورة، جامعة أبي بكر بلقاد تلمسان: الجزائر

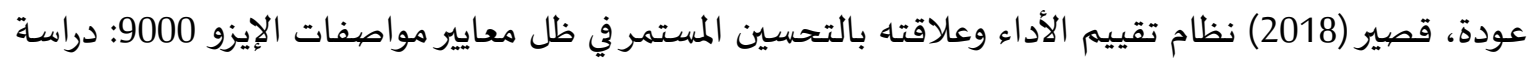

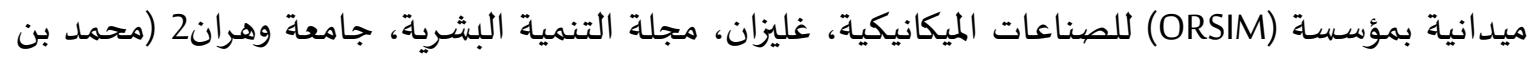
أحمد)، العدد 11، نوفمبر 2018: 103 - 118. غضبان، وهيبة؛ وعولمي، حسيبة (2019) فعالية إدارة المسار الوظيفي ودوره في تحسين أداء العاملين، دراسة

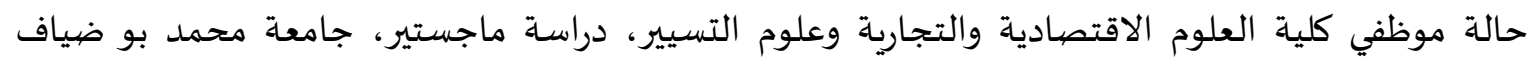
(المسيلة)، الجزائر.

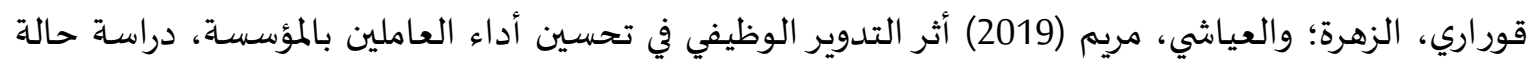

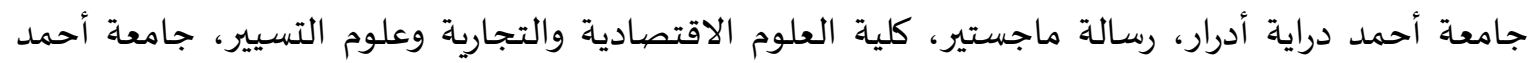
دراية أدرار - الجزائر. القيسي، محمد وائل (2016) الأداء الاستراتيجي الأمريكي بعد العام 2008، العبيكان للنشر والتوزيع، الرياض: المملكة العربية السعودية: 47 لعصب، عبد الهادي (2017) أثر تخطيط وتطوير المسار الوظيفي على تحسين أداء العاملين، رسالة ماجستير،

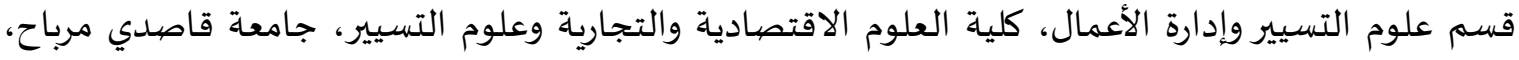
ورقلة، الجزائر.

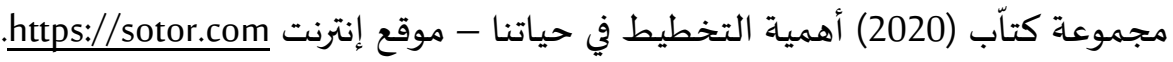
مصلح، ندى إبراهيم (2018) التأقلم التنظيمي كمتفيّر وسيط لقياس العلاقة بين تخطيط الماتيط المسار الوظيفي

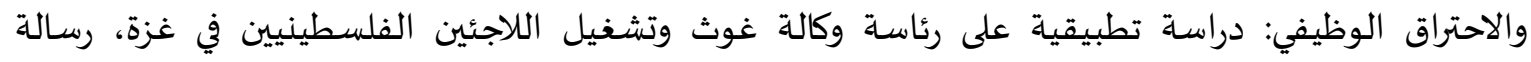

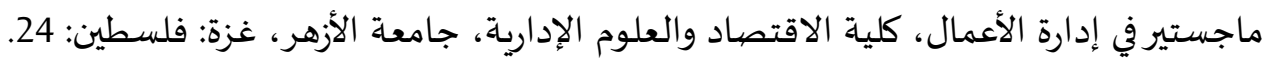

ثانيا- المراجع بالإنجليزية:

- Armstrong, M. (2016) Human Resources Management Practice, Cambridge University Press, $10^{\text {th }}$. Edition, UK, p.695

- Biswakarma, Gangaram (2016) Organizational Career Growth and Employees' Turnover Intentions: An Empirical evidence from Nepalese Private Commercial Banks, International Academic Journal of Organizational Behavior and Human Resource Management, Vol. 3, No. 2, p. 10- 26.

أثر التخطيط والتظوير للمسار الوظيفي على تحسين أداء الموظفين 
- Bratton, John \& Gold, Jeff (2017) Human resource management: Theory and Practice, Palgrave Macmillan, London.

- Cascio, Wayne (2018) Managing human resources, $11^{\text {th }}$. Edition, MacGraw- Hill Education.

- Chanin, Y. (2012) Influence Factors on Career Growth in the Hospitality Industry, The Asian Business and Management Conference, Mahidol University International College, Mahidol:Thailand.

- Felix, K. (2012) Career development practices among commercial banks in Kenya, University of Nairobi Library, Nairobi

- Gajanethi Swathi Kumari (2019) Reinventing the workplace - Strategic to Employee Career Development in Indian Telecom Industry - A Research, International Journal Of Engineering and Advance Technology (IJEAT) Vol. 9, Issue 2, pp. 5503- 5507.

- Hedge, Jerry and Rineer, Jennifer (2017) Improving Career Development Opportunities Through Rigorous Creer Pathways Research, RTI Press Publication, No. OP- 0037- 1703, Research Triangle Park, NC: RTI Press (https://doi.org/10.3768/rtipress.2017.op.0037.1703).

- I Wayan Manggis, Anik, Yuesti, and I Ketut, Setia Sapta (2018) The Effect of Career Development and Organizational Culture to Employee Performance with Motivation of Work as Intervening Variable in Cooperation in Denpasar Village, International Journal of Contemporary Research and Review, Vol. 9, Issue 07, pp. 20901- 20916.

- Ikechukwu, Dialoke and Paschal A. Jane Nkechi (2017) Effect of Career Growth on Employees Performance: A Study of Non- Academic Staff of Michael Okpara University of Agriculture Umudike Abia State, Nigeria, World Journal of Entrepreneurial Development Studies, Vol. 1, No. 1, pp. 1- 12.

- Kakui, I \& Gachunga, H. (2016) Effects of Career Development on Employee Performance in the Public Sector: A Case of National Cereals and Produce Board, Strategic Journal of Business and Change Management, 3 (3) pp.307- 324

- Mwashila, Harun, M. (2017) The Influence of Career Development on Academic Staff Performance in Kenyan Public Universities in Coast Region, Master Degree requirement in Business Administration, Human Resource Management Option, Business Administration College, Technical University of Mombasa, Kenya. 